\title{
Development and Validation of the Inviting Teaching Effectiveness Scale based on the Invitational Theory
}

Neaman M. S. Al-Musawi*

University of Bahrain, Kingdom of Bahrain

Solicited

\begin{abstract}
This study reports on a new instrument, the Inviting Teaching Effectiveness Scale (ITES), which is a 20-item measure based on the fundamental teaching competencies derived from the principles of Invitational Education (Purkey \& Novak, 1984). The initial instrument had included 30 items and was then validated on a random sample of $640 \mathrm{stu}-$ dents enrolled at the University of Bahrain. The final version of the developed Scale contains 20 items and measures four aspects of inviting teaching effectiveness: Invitational instruction, inviting relationships, invitational assessment and inviting classroom environment. As the new Scale displayed sound psychometric properties, it can be considered as a potentially useful tool to assess teacher performance and improve teaching practices at tertiary level of education. Information about test construction, reliability, validity, and generalizability are presented and implications and benefits associated with use of the instrument as a tool for measuring teaching effectiveness are discussed.
\end{abstract}

Keywords: Inviting Teaching Effectiveness, Invitational Theory, Scale Development, Validity, Reliability, Generalizability.

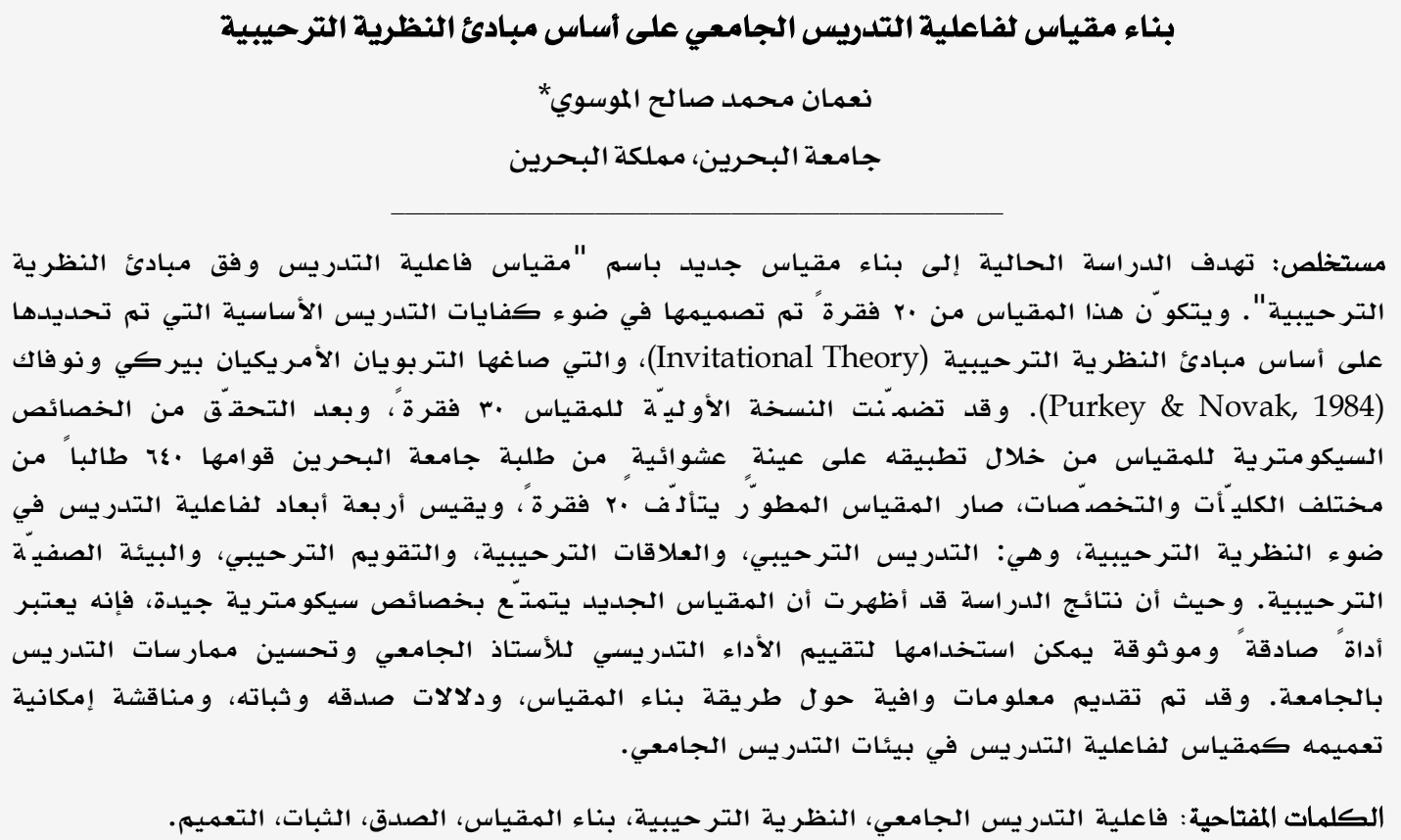


The past century has witnessed a proliferation of research on effective college teaching. As the 21st century approached, it became increasingly clear that greater investments in teacher preparation and development will be required to ensure that the teaching force is well-equipped to succeed at teaching much more challenging content to a much more diverse group of learners. Such reforms, many policymakers and practitioners believe, will in turn require comprehensive restructuring of the systems by which institutions of higher education license, hire, induct, support, and provide for the continuing learning of teachers (NBPTS, 1991; NCATE, 2002).

In the United States, standards for teacher education accreditation and for teacher licensing, certification and ongoing evaluation have become a prominent lever for promoting system-wide change in teaching (Darling-Hammond, \& Bransford, 2005).

The effort to define what teachers should know and be able to do to be successful and the use of assessments of such knowledge and skills to make decisions about entry and continuation in teaching has gained steam with the advent of new standards for student learning promulgated by both national associations and state governments. These standards posit "a more active, integrated, and intellectually challenging curriculum for all students, not just the most academically able". Thus, they also anticipate "more diagnostic teaching that provides multiple ways to learning, so that a wider range of students is enabled to succeed" (Darling- Hammond, 1999, p. 6).

In brief, the standards - known as the National Board for Professional Teaching Standards (NBPTS, 1991) - state that:

1. Effective Teachers are committed to students and their learning: They are dedicated to making knowledge accessible to all students. They treat students equitably, recognizing individual differences. They understand how students develop and learn, and aware of the influence and culture on behavior. They develop student's cognitive capacity and respect for learning. Equally important, they foster students' selfesteem and civic responsibility.

2. Effective Teachers know the subjects they teach and how to teach those subjects to students. Certified teachers have a rich understanding of the subject they teach and appreciate how knowledge in their subject is created, organized, linked to other disciplines and applied to realworld settings. They command specialized knowledge of how to convey and reveal subject matter to students, and of how to pose and solve one's problems.

3. Effective Teachers are responsible for managing and monitoring student learning. Accomplished teachers create instructional settings to capture and sustain the interest of their students and to make the most effective use of time. They know how to motivate and engage groups of students to ensure a purposeful learning environment. They regularly assess the progress of individual students as well as the class as a whole, and implement multiple methods for measuring student growth.

4. Effective Teachers think systematically about their practice and learn from experience. Striving to strengthen their teaching, certified teachers critically examine their practice, seek the advice of others, and draw on educational research to expand their repertoire, deepen their knowledge, sharpen their judgment, and adapt their teaching to new ideas and theories.

5. Effective Teachers are members of learning communities. Accomplished teachers contribute to the effectiveness of their institution by working collaboratively with other professionals on instructional policy, curriculum and staff development. They find ways to work in collaboration with parents, engaging them productively in the work of the institution. 
The main difficulty of building valid and reliable measures of effective college teaching is associated with the disagreement among educators about the proper understanding and interpretation of the concept "Effective Teaching". Frameworks for teaching, such as the one proposed by Danielson (1996) in response to the changing NCATE standards, possess limitations resulting from disparities that exist in the educational community regarding educational goals, assessment, and control of extraneous variables in educational research (Benjamin, 2002).

Firstly, appropriate educational goals are difficult to define. Members of the educational community still have not reached a consensus on what educational goals will be most effective in preparing students for the challenges of today and tomorrow.

Secondly, assessment measures currently used in educational research are inadequate for determining the comparative effectiveness of different approaches to teaching and learning. Valid and reliable instruments are urgently needed for the new generation of instructional goals.

Thirdly, extraneous variables in educational, as well as social research are difficult to control. Variables, such as random assignment of students and teachers to experimental and control groups, complicate a determination of what approaches to teaching are indeed most effective.

On the turn of this century, some educators and policymakers have embraced the philosophy of constructivism and a constructivist approach to teaching and learning (Phillips, 2000) that supports the notion that people's understanding of any concept depends entirely on their mental construction of that concept. Although teachers can guide the learning process, students must assume the responsibility of managing the process and developing an understanding for themselves. Despite the advantages of this approach to teaching and learning, constructivist assessment tools have not been yet widely developed and implemented in various educational settings.

\section{Theoretical Framework}

National Board for Professional Teaching Standards clearly reflects the basic constructs of Invitational Theory. The concept of Invitational Education was first introduced by Purkey in 1978 and represents a "process by which people are cordially summoned to realize their relatively boundless potential" (Purkey \& Novak, 1984, p. 3). This process is a perfect descriptor of the act of mentoring wherein an experienced individual serves in the role of friend and teacher to assist a "newcomer," in this case a beginning teacher, to develop into a more effective professional.

From the point of perceptual psychology, upon which invitational theory was developed, it is clear that to understand an individual's behavior we need to know how that individual perceives and interprets his/her life experiences. An individual's personal interpretation is more important than "objective reality" because an individual responds to one's own perception of reality and not to reality itself (Purkey \& Schmidt, 1996; Seligman, 1991).

Invitational theory focuses on five environmental areas (5 "Ps") that support or hinder an individual's success or failure. They include People, Places, Policies, Programs, and Processes (Purkey \& Novak, 1984).

"People" assesses respect, caring, and the honouring of diversity and refers to the positive or "inviting" influence of the teachers and support staff in the school. "Places" relates to the physical aspects of the school. "Policies" refers to the procedures, codes, and rules (written and unwritten), used to regulate the ongoing functions of individuals and organizations. "Programs" refers to the curriculum for students to develop both academically, physically, and socially inviting environment. "Processes" refers to such issues as cooperative spirit, democratic activities, values, and attitudes of students, teachers, administrators, and support staff

An inviting relationship, as Purkey and Schmidt $(1987$, p. 3) wrote, "has the potential to improve both the immediate human condition and the long-term growth and 
health of people. ... The inviting relationship is as much a therapeutic attitude, an orientation in character, a 'dispositional quality,' as it is a methodology. As such, it can be applied to interactions with people in a wide variety of places", as far as it is based on widely accepted values, such as optimism, trust, respect, care, and intentionality, which is a belief, underlying behavior with a purposeful direction and aim.

Professionals who apply the principles of invitational theory and practice adhere to three foundations (Purkey \& Novak, 1984: 19):

1. Democratic Ethos: emphasize deliberative dialogue, mutual respect, and the importance of shared activities between teachers and students, where they have to work together to construct the ethical character, social practices and educational institutions that promote a fulfilling shared life. In terms of effective teaching, this principle reflects the teacher's commitment to students and their quality of learning.

2. Perceptual Tradition: This principle postulates that how a person chooses to behave depends upon how they perceive the world and themselves in it. Each of us has our own reality built upon the present and our past experiences. Within this context, effective teachers think critically about their practice and learn from their own experience.

3. Self-concept Theory: This principle postulates that the maintenance, protection, and enhancement of the perceived self are the basic motivating factors behind all human behavior. This means that the effective teacher would benefit from self-assessment in planning how to have a deep knowledge of the subject matter, methods of teaching and assessment, and to work collaboratively with parents and other professionals in the field to manage and monitor student's learning.
Professionals also adhere to four fundamental assumptions. Shaw, et al. (2013, p. 107) summarize these beliefs as follows:

1. People are able, valuable, and capable of self-direction, and should be treated accordingly (this belief demonstrates Trust and Respect).

2. Helping is a cooperative, collaborative alliance in which process is as important as product (Care and Optimism).

3. People possess relatively untapped potential in all areas of human development (Intentionality).

4. This potential can best be realized by places, policies, and programs that are intentionally designed to invite development, and by people who consistently seek to realize this potential in themselves and others, personally and professionally (Intentionality).

Schmidt (2004, p. 43) believes that successful relationships are "established through the intentional creation of beneficial messages chosen and sent within a caring context that dependably demonstrates optimism, trust, and respect for all persons involved in the process".

The welcoming invitational educational theory may serve as a "useful tool for universities to meet the needs of all students, especially those new to the university system" (Varvisotis, et al., 2020, p. 46). In this setting, the need for invitational practice is not only more demanding, it is necessary if the freshmen are going to succeed. According to Nicholson, "Ultimately, to be successful in a classroom, you have to understand what a professor's expectations are, but also the right way to express concerns and questions" (in Musto, 2017, p. 3). In a study conducted by ELS Educational Services, freshmen shared concerns about their professors that suggest an invitational way to introduce them to the academic setting in American universities:

- They wished their professors would provide additional helpful criticism. 
- They wished professors would try harder to understand the new student experience.

- They wished professors would provide some non-typical examples in class

- materials (Nicholson in Musto, 2017, p. 2).

The IAIE's starfish model (Purkey \& Novak, 2008) can and should be incorporated as students enter university classrooms. This model presents five points (i.e., the legs of a starfish):

- Put PEOPLE first.

- Establish fair POLICIES.

- Share collaborative and evaluative POLICIES.

- Develop stimulating and engaging PROGRAMS that are respectful to all

- Students from all cultures.

- PROVIDE an inviting and warm environment that is welcoming to all.

This model can be incorporated by expecting the following classroom processes from university professors and by infusing them into all courses (Hotaman, 2010). Opportunities that allow students to be instructed in an invitational manner include the following:

- Instruction should be comprehensible to all learners.

- Learning should be interactive.

- Instruction should be cognitively challenging.

- Instruction should connect the university experience to the learners' lives and promote cross-cultural understanding.

- Learners should be allowed to share ideas and methods from their own cultures.

- Instruction should develop language and literacy across the academic curriculum.
- The goal of instruction should be achievement of academic standards by all

- Learners, regardless of their culture or identity or native language.

Truly, the use of thoughtful, intentionally inviting communication continues to create opportunities for optimal human potential. It was crucially beneficial to model IE theory and practices to teacher candidates. However, it is interesting to observe how many teacher candidates or novice instructors seem afraid to treat students in a caring, optimistic manner that builds mutual respect and trust. It seems they misunderstand kindness as weakness and fear potential behavioral problems would results, causing them to be viewed as less capable. Too often, inexperienced teachers express fear being perceived as unprofessional. Somehow, they believe a learned "spare the rod and spoil the child" approach is best. The result in such utilization is a stern demeanor and use of forceful language and tone. Therefore, it is invaluable to help teacher candidates understand the positive results from implementing IE theory and practices (Evans, 2019, p. 33).

\section{Research Problem}

Given the need for an instrument that measures the quality of teaching at university, a research-oriented example of how the invitational approach to education is applied to measuring effective college teaching is provided.

First Fundamental Principle: The teacher accepts and affirms the belief that his (her) "students are able, valuable, and capable of self-direction, and should be treated accordingly (Shaw, et al., 2013, p. 31).

This principle can be realized if the teacher can perform the following tasks:

1. Demonstrating openness to the different opinions of students in class.

2. Showing friendliness and respect for students inside and outside class.

3. Taking student's interests when setting concrete dates for tests. 
4. Being sensitive to students' interests and conditions when determining course requirements.

5. Being flexible and curious in dealing with students inside and outside the classroom.

Second Fundamental Principle: The teacher accepts and affirms the belief that helping is a cooperative, collaborative alliance in which the process is as important as the product.

This principle might be achieved if the teacher can perform the following:

1. Submitting clear on-line presentations and explanations of course content.

2. Providing necessary help with student's study and academic problems.

3. Providing frequent and quality feedback to students when discussing their test results.

4. Providing help to each student to increase one's level of achievement.

5. Providing clear answers to student's questions and relevant queries.

Third Fundamental Principle: The teacher accepts and affirms the belief that People possess relatively untapped potential in all areas of human development. This principle might be achieved if the teacher can perform the following tasks:

1. Introducing intellectually challenging ideas and problems that prompt the student's independent thought and curiosity in the classroom.

2. Asking students to carry out definite course-based, open-ended tasks and projects that promote critical thinking and problem-solving abilities.

3. Constructing tests and quizzes of questions that tap the student ability to critically analyze and synthesize information based on the course content.

4. Including items of different formats (e.g., multiple-choice, true-false, essay, etc.) in tests and quizzes to meet different student abilities and levels.
5. Scoring exam papers and grading students in a way that shows the extent of growth of a student's knowledge, ability and skills throughout the course.

Fourth Fundamental Principle: The teacher accepts and affirms the belief that human potential can be best realized by places, policies, and programs that are intentionally designed to invite development, and by people who consistently seek to realize this potential in themselves and others, personally and professionally. This principle might be achieved if the teacher can perform the following tasks:

1. Using the time available for instruction efficiently while monitoring the student's level of understanding and apprehending new information.

2. Being available to give constructive help for students during office hours.

3. Creating a participatory learning environment where students can be involved in active learning, succeed and grow personally and professionally.

4. Being committed to the teaching procedures (e.g., teaching plan, exam dates, teaching and assessment methods, etc.) adopted at the university.

5. Using differing programs (e.g., enriching, remedial, etc.) to ensure that the personal and professional development of different students is achieved.

Given that the previous studies based on the tenets of the invitational theory were conducted within the school environment (e.g., Evans, 2019), and that the existing instruments purport to assess the qualities of the global school climate (Smith \& Barnard, 2004), the main beliefs of invitational education have served as a profound basis to construct the initial version of the Inviting Teaching Effectiveness Scale (ITES) that is designed to measure the invitational qualities of effective teaching at the university. It contains 30 items clustered around the four assumptions of invitational theory. 


\section{Method}

Participants: A random sample of 686 students enrolled at the University of Bahrain completed the 30-item instrument. Although 686 instruments were completed, $46(6.7 \%)$ had 10 or more missing data or were inappropriately completed and were thus eliminated from further analysis. The final sample (640 students) consisted of 285 male students and 355 female students with a mean age of 20.04 years. Students volunteered to participate in the study either in the development sample $(n=412)$ or validation sample $(\mathrm{n}=228)$.

Instruments: The Inviting Teaching Effectiveness Scale (ITES) is a self-report 20item instrument based on the Invitational Education model (Purkey \& Novak, 1984). All items pertain to the university environment and were designed to assess the qualities of effective teaching in the areas of people, places, policies, programs, and processes. Respondents report their agreement with each item on a five-point response scale, where $1=$ Strongly Agree, 2 = Agree, 3 = Undecided, $4=$ Disagree, and $5=$ Strongly Disagree.

The development process included four stages: a) Generating an item pool, b) Reviewing the items by experts, c) Pilot study, d) Validity and reliability study, and e) Selecting the final items.

a) In item generation phase, the primary concern is content validity, which Wynd, et al. (2003) defined as the "extent to which an instrument adequately samples the research domain of interest when attempting to measure phenomena" (p. 509). In this study, content validity was achieved based on the related theory of invitational education (Purkey \& Novak, 1984). As a result, an experimental 25-item form that tapped the four principles of invitational theory was built. The construction of the items followed the rules specified in the relevant literature (e.g., Robinson \& Leonard, 2019).

b) Reviewing the items by experts: The experimental form of the ITES was then presented to eight experts from the field of Educational Psychology who were informed about the topic of the study and were asked to examine the items. A triple rating was used, which included "proper", "unnecessary" and "improper" options for each item. All expert forms were unified under one form and content validity rate was obtained by calculating the Content Validity Index for Scales (S-CVI, Polit \& Beck, 2006, p. 492) being, for more than two judges, the "proportion of items on an instrument that achieved a rating of 3 or 4 by all content experts". The average proportion of items rated relevant across experts was .80 . Accordingly, 5 items were removed from the scale in line with the content validity rate calculation.

c) The pilot study: A form consisting of 20 items was created after these steps. Score intervals which are used in the assessment regarding the option and the evaluation of these options are as follows: Option score interval "Strongly disagree" 1.00-1.80; "Disagree" 1.81-2.60; "Indecisive" 2.613.40; "Agree" 3.41-4.20; and "Strongly agree" 4.21-5.00. The aim of the pilot study was to investigate whether the Inviting Teaching Effectiveness Scale consists of one or more dimensions and whether it measures the level of inviting college teaching effectiveness as perceived by the participants. To achieve this aim, participants voluntarily completed the instrument during their regular classroom lectures at the University and assured of anonymity. Between 30-45 minutes was required to complete the 25-item instrument. They were asked to read each item first, and then evaluate it by indicating the extent to which it contributes to effective college teaching.

d) Validity and reliability analyses were performed with SPSS 23.0. In order to determine the construct validity of the scale, exploratory factor analysis was applied. Following a protocol used by Egan, et al. (2007), the principal component analysis was used to identify the factor structure. To maximize the reliability of the presumably correlated factors, alpha factor analysis with oblique rotation was used. Factor retention criteria were an eigenvalue $>1$, and the point on the scree plot that shows a distinct break between the steep slope of the large factors and the gradual tailing off 
of the remaining factors. The results of factor analysis are displayed in Table 1.

In addition, the criterion-related validity of the ITES was obtained. For this purpose, some participants $(n=154)$ completed the Teacher Human Qualities Questionnaire (THQQ), which was designed to examine the human qualities (caring, motivation, respect, interactions with students personal traits) of the university teacher as perceived by undergraduate students (Al-Musawi \& Karam, 2011, p. 187), to determine the strength of relationship with the ITES. A correlation coefficient of $\mathrm{r}(154)=.37, \mathrm{p}<.01$ indicated a moderate, positive relationship, thus showing the criterion validity of ITES. Also, a reliability analysis that focused on internal consistency to identify individual items that correlated well within the scale was used.

e) Selecting the final items: To retain the scale items, item retention criteria were item-total correlation $\geq .30$, factor loading $\geq .40$ and commonality $\geq .20$ on all parameters. Using these criteria, the 25 -item scale was reduced to a 20-item scale, the ITES. Scores on the ITES ranged from 20 to 100, where high scores reflected more effective teaching and low scores - less effective.

\section{Results}

\section{Development Sample}

Correlations among the 25 individual items of the ITES were factorially analyzed by the principal component method with Oblimin rotation in view of the assumption that the factors are correlated.

Initial examination of the eigenvalues and scree plot generated by factor analyzing the 25-item initial scale suggested a sixfactor solution that accounted for $47.63 \%$ of the total variance. However, this sixfactor solution was neither conceptually sound nor readily interpretable. Factor loadings ranged from .15 to .69 and 23 items loaded on the first three factors, but only 7 items loaded on the last three factors. Also, a reliability analysis indicated that internal consistency of the 25-item initial scale measured by coefficient alpha was .72 and the mean item-total correlation was .33. Clearly, some items func- tioned better than others, and some items were retained for further consideration based on the retention criteria described earlier. This selection process reduced the 25 -item initial scale to a 20 -item scale - the ITES.

Development sample data were then reanalyzed using only the ITES. Examination of the resulting eigenvalues and the scree plot indicated a conceptually sound, readily interpretable four-factor solution that accounted for $44.42 \%$ of the variance. Factor loadings ranged from .41 to .66 . The internal consistency of the ITES measured by coefficient alpha was .81 , and the mean item-total correlation was .39. Internal consistencies of the ITES's four factors using coefficient alpha were $.81, .84, .80$, and .77 , respectively.

Exploration of the meaning of items revealed four factors, each consisting of 5 items. Factor 1, labeled invitational instruction, assessed teaching methods and emphasized important criteria, such as encouragement of student's independent thought and concern to using the lecture's time efficiently for the sake of students. Factor 2, labeled inviting relationships, consisted of items on teacher's sensitivity to students' interests when setting concrete dates for tests and his/her response to students' suggestions relevant to the course. Factor 3, labeled invitational assessment, was concerned with the teacher's accuracy and fairness in scoring exam papers and grading students while items of Factor 4, labeled inviting classroom environment, were related to the participatory learning environment where students can be involved in active learning, succeed personally and professionally (Table 1).

\section{Validation Sample}

Initial examination of the eigenvalues and scree plot generated by factor analyzing the ITES suggested a five-factor solution that accounted for $52.43 \%$ of the variance. However, the fifth factor's eigenvalue of 1.08 was only slightly above the standard minimum of 1.00 for factor formation (Kaiser \& Rice, 1974). Furthermore, the fifth factor correlated .06, .07, .04, .10, respectively, with the other four factors, and these other factors correlated .48 among 
Table 1

The Inviting Teaching Effectiveness Scale Factor Structure, and Factor Loadings from the Development and Validation Samples

\begin{tabular}{|c|c|c|c|c|c|c|c|c|}
\hline & \multicolumn{2}{|c|}{ Instruction } & \multicolumn{2}{|c|}{ Relationships } & \multicolumn{2}{|c|}{ Assessment } & \multicolumn{2}{|c|}{ Environment } \\
\hline Item & DS & VS & DS & VS & DS & VS & DS & VS \\
\hline $\begin{array}{l}\text { Relating the course content to the learner's } \\
\text { environment }\end{array}$ & 0.63 & 0.67 & & & & & & \\
\hline $\begin{array}{l}\text { Giving clear explanations and online presenta- } \\
\text { tions of course material and content }\end{array}$ & 0.55 & 0.52 & & & & & & \\
\hline $\begin{array}{l}\text { Using method of teaching that is consistent } \\
\text { with the content, student abilities and levels }\end{array}$ & 0.50 & 0.56 & & & & & & \\
\hline $\begin{array}{l}\text { Being committed to the course plan that is } \\
\text { adopted at the beginning of the semester }\end{array}$ & 0.44 & 0.51 & & & & & & \\
\hline $\begin{array}{l}\text { Showing concern to using the lecture's time } \\
\text { efficiently for the sake of students }\end{array}$ & 0.46 & 0.48 & & & & & & \\
\hline $\begin{array}{l}\text { Responding to students' interests in setting } \\
\text { concrete dates for tests and quizzes }\end{array}$ & & & 0.66 & 0.72 & & & & \\
\hline $\begin{array}{l}\text { Being flexible and curious in dealing with stu- } \\
\text { dents inside and outside the classroom }\end{array}$ & & & 0.60 & 0.62 & & & & \\
\hline $\begin{array}{l}\text { Being sensitive to students' interests and condi- } \\
\text { tions when setting course requirements }\end{array}$ & & & 0.54 & 0.53 & & & & \\
\hline $\begin{array}{l}\text { Providing necessary help with student's study } \\
\text { and academic problems }\end{array}$ & & & 0.47 & 0.50 & & & & \\
\hline Being friendly and respectful with all students & & & 0.42 & 0.44 & & & & \\
\hline $\begin{array}{l}\text { Constructing test questions that are relevant to } \\
\text { the content taught in the class }\end{array}$ & & & & & 0.60 & 0.65 & & \\
\hline $\begin{array}{l}\text { Asking relevant, clear and accurate questions } \\
\text { in tests and classroom quizzes }\end{array}$ & & & & & 0.53 & 0.54 & & \\
\hline $\begin{array}{l}\text { Giving a grade to each student according to his } \\
\text { or her actual level of achievement }\end{array}$ & & & & & 0.48 & 0.43 & & \\
\hline $\begin{array}{l}\text { Being accurate and fair when scoring exams } \\
\text { and grading }\end{array}$ & & & & & 0.46 & 0.41 & & \\
\hline $\begin{array}{l}\text { Providing frequent and quality feedback to } \\
\text { students when discussing test results. }\end{array}$ & & & & & 0.41 & 0.45 & & \\
\hline $\begin{array}{l}\text { Asking frequent questions that promote critical } \\
\text { thinking and problem-solving abilities. }\end{array}$ & & & & & & & 0.64 & 0.66 \\
\hline $\begin{array}{l}\text { Showing openness to the different opinions of } \\
\text { students }\end{array}$ & & & & & & & 0.60 & 0.65 \\
\hline $\begin{array}{l}\text { Using the time of instruction efficiently while } \\
\text { monitoring understanding of information }\end{array}$ & & & & & & & 0.51 & 0.62 \\
\hline $\begin{array}{l}\text { Encouraging of questions and active discus- } \\
\text { sions in the class }\end{array}$ & & & & & & & 0.45 & 0.40 \\
\hline $\begin{array}{l}\text { Creating an environment in the class that pro- } \\
\text { motes active learning and student growth }\end{array}$ & & & & & & & 0.45 & 0.43 \\
\hline Eigenvalue & 4.48 & 4.86 & 3.71 & 3.24 & 1.74 & 1.94 & 1.08 & 1.68 \\
\hline$\%$ variance explained & 22.24 & 32.51 & 10.10 & 9.81 & 6.72 & 5.58 & 5.36 & 5.11 \\
\hline Alpha coefficient & 0.81 & 0.85 & 0.84 & 0.83 & 0.80 & 0.82 & 0.77 & 0.79 \\
\hline
\end{tabular}

themselves. With this in mind, a higher minimum eigenvalue for factor formation was set and a second factor analysis was conducted. This second factor analysis produced a conceptually sound, readily interpretable four-factor solution that accounted for $53.01 \%$ of the variance. Factor loadings ranged from .40 to .72. The internal consistency of the ITES measured by coefficient alpha was .89 , and the mean item-total correlation was .43. Internal consistencies of the ITES's four factors were $.85, .83, .82$, and .79 , respectively. The similarity in internal consistency across the development and validation samples demonstrates the ITES's cross-sample generalizability (refer to Table 1).

\section{Discussion}

Results of this study suggest that the ITES is a reliable and valid instrument for evaluating teaching effectiveness among college students from the perspective of Invitational theory. Factor and reliability analyses demonstrate a stable factor structure with generally good internal reliability across development and validation samples. These results provided additional 
evidence for the adequacy of the invitational theory as a reliable source for conceptualization of effective teaching as perceived by students.

The resulted measure includes only 20 items, which makes it easy for quick and efficient use in the classroom setting at the University. The ITES items can be used to evaluate college teaching as they clearly demonstrate the relationship between teacher characteristics and student achievement. The new measure can also be utilized to evaluate teacher performance with the aim of improving teaching practices in higher education institutions.

Invitational theory argues that learning is enhanced when learners are positively encouraged or 'invited' into the educational experience. Arising from perceptual and self-concept theory, the invitational pedagogy is constructed on four principles: respect for people, trust, optimism and intentionality, and upon five pillars: people, places, policies, programs and processes. Its main contributions address the psychogeography and the constructive alignment of learning environments with student needs and the training of teachers and counsellors (Haigh, 2011; Moss, 2018).

In the light of the results of study, instructors at universities that support teacher education programs have a unique opportunity to infuse the practice of invitational education into their course cultures by modeling and encouraging the tenets of the invitational education theory, which was originally developed at the University of Florida in 1968.

It is time to infuse and reinfuse the seeds planted and allow invitational education to flourish on college campuses once again, moving theory into practice at the tertiary level. Higher education offers learning opportunities to its participants in traditional brick and mortar settings as well as in online settings. Invitational education practices can be used to support inperson or online instruction in higher education with the aim of improving teaching practices in higher education institutions (Matyo-Cepero, et al., 2017).

\section{References}

Al-Musawi, N., \& Karam, E. M. (2011). Humanistic qualities of the teacher as perceived by undergraduate students in Bahrain and Kuwait. Journal of Education for Teaching, 37(2), 183-197.

Benjamin, W. (2002). Development and validation of student teaching performance assessment based on Danielson's framework for teaching. Paper presented at the Annual Meeting of the American Educational Research Association (New Orleans, LA, April 1-5, 2002). (ERIC Document Reproduction Service No. ED471552).

Darling-Hammond, L., \& Bransford, J. (Eds.) (2005). Preparing teachers for a changing world: What teachers should learn and be able to do. Jossey-Bass.

Egan, P. J., Canale, J. R., del Rosario, P. M., \& White, R. M. (2007). The Academic Rational Beliefs Scale: Development, validation, and implications for college counselors. Journal of College Counseling, 10, 175-183.

Evans, M. (2019). Transforming a rural elementary school through invitational education practices. Journal of Invitational Theory and Practice, 25, 25-36.

Haigh, M. (2011). Invitational education: Theory, research and practice. Journal of Geography in Higher Education, 35(2), 299-309.

Hotaman, D. (2010). The teaching profession: Knowledge of subject matter, teaching skills and personality traits. Procedia Social and Behavioral Sciences, 2, 1416-1420.

Kaiser, H. F., \& Rice, J. (1974). Little Jiffy Mark IV. Educational and Psychological Measurement, 34, 11-117.

Matyo-Cepero, J. A., Varvisotis, S., \& Lilienthal, L. K. (2017). Using the tenets of invitational education to create an inviting classroom in higher education. Delta Kappa Gamma Bulletin, 83(5), 11-14.

Moss, J. D. (2018). Inviting autonomy: Common roots and beliefs of selfdetermination theory and invitational 
education theory. Journal of Invitational Theory and Practice, 24, 17-28.

Musto, P. (2017). International students face similar challenges in the United States. Learning English. Retrieved from https://learning english.voanews.com

National Board for Professional Teaching Standards (NBPTS) (1991). Toward high and rigorous standards for the teaching profession. Author.

National Council for Accreditation of Teacher Education (NCATE) (2002). Professional standards for the accreditation of schools, colleges, and departments of education. NCATE.

Phillips, D. C. (Ed.) (2000). Constructivism in education: Opinions and second opinions on controversial issues. The University of Chicago Press.

Polit, D. F., \& Beck, C. T. (2006). The Content Validity Index: Are you sure you know what is being reported? Critique and recommendations. Research in Nursing and Health, 29, 489-497.

Purkey, W. W., \& Novak, J. M. (1984). Inviting school success: A self-concept approach to teaching and learning. Belmont, CA: Wadsworth.

Purkey, W. W., and Novak, J. M. (2008). Fundamentals of invitational education. GA: International Alliance for Invitational Education.

Purkey, W., \& Schmidt, J. (1996). Invitational counseling: A self-concept approach to professional practice. Brooks/Cole.

Purkey, W. W., \& Schmidt, J. J. (1987). The inviting relationship: An expanded perspective for professional counseling. Prentice-Hall, Inc.

Robinson, S. B., \& Leonard, K. F. (2019). Designing quality survey questions. Sage publications.

Schmidt, J. J. (2004). Diversity and invitational theory and practice. Journal of Invitational Theory and Practice, 10, 2645.
Seligman, M. E. P. (1991). Learned optimism: The skill to encounter life's obstacles, large and small. New York: Random House.

Shaw, D. E. Siegel, B. L., and Schoenlein, A. (2013). The basic tenets of invitational theory and practice: An invitational glossary. Journal of Invitational Theory and Practice, 19, 30-37.

Smith, K. H., \& Barnard, J. (2004). The psychometric properties of the Invitational School Survey (ISS): An Australian study. Journal of Invitational Theory and Practice, 10, 7-26.

Varvisotis, S., Matyo-Cepero, J., \& Tracy, G. E. (2020). Meeting the needs of international students through invitational education. The Delta Kappa Gamma Bulletin, 86(3), 44-50.

Wynd, C. A., Schmidt, B., \& Schaefer, M. A. (2003). Two quantitative approaches for estimating content validity. Western Journal of Nursing Research, 25, 508-518. 